\title{
Assessing speed enforcement policy measures by analyzing multi sustainability criteria
}

\author{
L. Vermote ${ }^{1}$, F. Van Malderen ${ }^{1}$, C. Macharis ${ }^{1} \&$ K. Putman ${ }^{2}$ \\ ${ }^{I}$ Department MOSI-Transport \& Logistics MOBI, \\ Vrije Universiteit Brussel, Belgium \\ ${ }^{2}$ Departement MESO, Vrije Universiteit Brussel, Belgium
}

\begin{abstract}
Sustainability assessment is generally used to identify the unsustainable effects of policy measures, such as sustainable transport policy strategies. Still, sustainability effects of road traffic safety policy measures are insufficiently studied. This paper will assess the sustainability of speed enforcement policy measures on highways. A multicriteria evaluation framework, containing social, economic and environmental assessment criteria, evaluates different speed enforcement policy alternatives. The framework determines how the policy alternatives meet the criteria, ranking the policy alternatives according to their sustainability. Results show that intelligent speed enforcement strategies are more sustainable than automatic and manned speed enforcement strategies. Multicriteria analyses have proved to be very useful for assessing sustainability. They provide compromise solutions for conflicting objectives.

Keywords: speed enforcement, sustainability assessment, multicriteria analysis.
\end{abstract}

\section{Introduction}

Policy measures are generally used to accomplish objectives. However, many policy implementations imply unexpected effects. Policy evaluation can be significant to identify unexpected policy effects. Sustainability assessment is an evaluation instrument to identify policy effects, which considers the social, economic and environmental impact of policy measures. The sustainability assessment tool is commonly used to enhance sustainable decision-making on complex decisions, like sustainable transportation. Multiple studies show that sustainable transport policy measures influence social, economic and ecologic 
dimensions of the society $[1,2]$. However, unexpected social, economic and ecologic effects of road traffic safety policy measures remain presently unclear. Few studies relate traffic safety evaluations to sustainability evaluations. The "sustainable safety" concept was launched in the early 1990s [3] to prevent accidents, and where it is not possible, to reduce the likelihood of severe injury to (nearly) zero. Sustainability is in this context intrinsic related to traffic safety. For this reason, this study expands sustainable safety to the sustainability of road traffic safety policy measures. Social, economic and environmental effects of road traffic safety policy measures are assessed. The initial Dutch sustainable safety objectives are mainly related to the social dimension. Our assessment framework adds economic and environmental criteria to the evaluation. Moreover, next to the explicit social traffic safety criterion, supplementary social assessment criteria are added to the evaluation framework.

Speed behaviour influence is a major strategy in road traffic safety policies. One out of three fatal accidents is caused by excessive or inappropriate speed [5]. Many studies discuss the strong correlation between speed intensity and traffic safety $[6,7]$. Higher speeds increase accident severity and the likelihood of accidents to occur. Exceeding the speed regime is probably the most frequent traffic violation [8]. Hence, speed enforcement is a crucial instrument in compelling the appropriate speed behaviour. Enforcement strategies can be subdivided in automatic, manned and intelligent speed enforcement. Manned procedures involve physical contact with police forces. Automatic strategies rely on license plate registration by speed cameras, while intelligent strategies add general positioning system (GPS) usage. Because excessive speed on highways cannot be compelled in a physical way (road surrounding, speed humps, etc.), automatic and manned speed enforcement is commonly applied. Intelligent speed enforcement offers future perspectives. This paper assesses the sustainability of speed enforcement policy measures on highways. Five speed enforcement alternatives for highways will be evaluated by social, economic and environmental criteria.

Sustainability challenges involve (1) complex decision-making and (2) problems of incommensurability. This study wants to demonstrate that the multicriteria analysis is a well-suited evaluation framework for decision-making regarding sustainability. The multicriteria methodology takes each challenge into account.

(1) Sustainable speed enforcement implementations on freeways involve social, economic and ecologic effects. Considering all the different effects of the multiple policy options can cause disagreement among groups of decisionmakers, resulting in indecision. Hence, the multi criteria analysis can guide and support group-level decision-making [9]. The multicriteria analysis segregates the decision problem into a goal, different policy alternatives and relevant evaluation criteria. Subsequently, the importance of each assessment criterion is considered by weighting each criterion against the final goal of the assessment. The eventual weighted decision tree gives the decision-makers a standardised overview of the decision problem. 
(2) Overcoming the problem of incommensurability is the second challenge. A quantified resume, containing advantages and disadvantages of the alternatives can assist the policy-makers in their actual decision. Still, the assessment of sustainability issues involves multiple social and ecologic criteria that are by nature difficult to quantify and monetarize $[10,16]$. The multicriteria analysis provides a resume, containing advantages and disadvantages of the alternatives, without the necessity to monetarise these effects. The incommensurability of qualitative effects is solved by ascribing relative ratio scores per criteria to each alternative, based on the pairwise comparison social choice application. Integrating qualitative criteria in their own nature make multicriteria analysis very suitable to carry out sustainability evaluations. Pairwise comparison of all policy alternatives, in relation to each sustainability criterion, results in the most probable policy alternative with respect to sustainability.

Section 2 elucidates the structure, the components and the process of the multicriteria analysis. Section 3 selects indicators for each criterion, assisting policy-makers in setting priorities per policy alternative. Section 4 discloses the results of the multi criteria analysis.

\section{Multi criteria decision structure}

Cost-benefit analysers are generally used to assist policy makers in their decision process. However, choices between policy alternatives cannot only be related to costs and benefits of a particular alternative. This reductionists approach is merely supported by one (economic) dimension. To avoid reductionism, additional dimensions and objectives of other scientific disciplines must be considered. The multicriteria approach, which is multi-dimensional in nature, enhances compromising and harmonising solutions between different scientific objectives. This asset makes the multicriteria analysis a very effective application in multi-inter-disciplinary contexts [11].

The Analytic Hierarchy Process, developed by Saaty [11], is one of the most frequently used multicriteria analyses. The method is based on the three principles (1) construction of the hierarchy, (2) priority setting and (3) logical consistency [14]. Complex decisions are hierarchically structured into subcomponents (criteria, sub criteria and alternatives) in order to achieve an overall objective. Subsequently, criteria and sub criteria are weighted according the preference of the assessor (step 1). The pairwise comparison mechanism (step 2) enables the decision-maker to ascertain values (relative priority) to each criterion related to the policy alternative, expressed on 1-9 ratio scale. The consistent performance controlling mechanism (step 3) ensures that the consistency ratio does not exceed the level of $10 \%$ when the assessor sets priorities. Finally, a priority matrix is constructed, ranking the most plausible policy alternatives in relation to the objective of the assessment. 


\subsection{Defining the policy alternatives}

To enforce sustainable speed enforcement strategies on freeways, different policy options can be wielded. Speed enforcement can be subdivided in manned, unmanned and intelligent speed enforcement.

\subsubsection{Unmanned speed cameras}

Unmanned speed cameras are frequently implemented on road sections with a high accident concentration, like black spots. Non-automatic speed enforcement on these road sections would be very time consuming or ineffective regarding the high traffic volumes. Unmanned speed cameras induce accident reductions and mean speed reductions. This study considers unmanned speed cameras as visible speed cameras. Drivers can anticipate on the camera because they can be noticed.

\subsubsection{Manned speed surveillance with interception}

Manned speed surveillance with interception comprises an observation team and an arresting team. The observation team performs the speed surveillance by means of radar control, laser gun or mobile speed cameras. When a driver violates the speed limit, the observation team sends the properties of the vehicle to the downstream arresting team. The arresting team will stop the violator and write a penalty. Manned speed surveillance policy alternatives are in this study regarded as invisible enforcement strategies. Drivers cannot anticipate on the surveillance because it is not compelled on fixed locations.

\subsubsection{Manned speed surveillance without interception}

Manned surveillance without interception consists of a mobile observation team only. This enforcement strategy is part of the automatic speed enforcement category, since it involves no physical contact with the violator. The observation team exerts the speed surveillance by means of radar technology, laser gun or speed cameras on unannounced and invisible locations.

\subsubsection{Section control}

Section control is a relatively new speed enforcement strategy, which is predominantly enforced on freeways and ring ways. The enforcement strategy compels larger distances (predominantly 2- till $5 \mathrm{~km}$ ), instead of a certain point on the road. Section control registers the speed of the vehicle over the whole section, relying on different cameras. Subsequently the actual driven speed over the complete section is calculated over the registered time interval. Section control speed enforcement is indicated and implemented $24 \mathrm{~h}$ per day and 7 days per week.

\subsubsection{Intelligent speed adaptation}

Intelligent speed adaptation is a collective noun for multiple feedback systems, which keep track of vehicle speed related to the prevailing speed limit. Advanced technologies assist the enforcement strategy by means of GPS and geographic speed databases. Different types of ISA can be implemented. Open ISA systems 
merely inform or warn the driver. Half-open ISA systems intervene with active accelerators when the appropriate speed is violated. Closed ISA systems rely on a speed restricting intervening system to compel the speed limit [13].

\subsection{Selecting assessment criteria}

Different sustainability criteria have been selected to evaluate the policy alternatives. Assessment criteria are structured according to a social, economic and environmental dimension. Distinct dimensions are important to provide balanced sustainability evaluations. The three sustainability assessment criteria comprise different sub criteria, which support main objectives of the Flemish road traffic safety policy plan [14]. Additional relevant sub criteria are derived out of the European Commission's impact assessment guidelines [15] supported by a meta-analysis of more than 1.700 road safety evolution studies [10].

\subsubsection{Social criteria}

The category of social criteria comprises the sub criteria traffic safety, traffic livability and attitudes. The traffic safety sub criterion assesses the contribution of each policy alternative to injury and fatal accident reduction. Possible reductions in noise and atmospheric gasses emitted by vehicles are determined by the traffic livability sub criterion. Finally, driver attitudes towards the different speed enforcement policy measures on highways are investigated.

\subsubsection{Economic criteria}

The sub criteria traffic flow, implementation costs and operational costs establish the economic assessment criteria category. Each policy alternative has a specific impact on freeway traffic flows. Moreover, each policy option will involve certain implementation costs to enforce the alternative. To keep on enforcing excessive speed the particular alternative will require additional costs, which are assessed by the operational cost sub criterion.

\subsubsection{Environmental criteria}

The environmental criteria category contains the sub criteria greenhouse gas emissions and minimizing waste. Speed enforcement strategies evoke variations in greenhouse gas emissions, since they influence vehicle acceleration. The minimizing waste sub criterion assesses the amount of primary products that is necessary to enforce the alternative.

\subsection{Synthesizing judgements}

The decision problem, i.e., goal of the assessment, criteria, sub criteria, weights and policy alternatives, is inserted into the Expert Choice software programme. Each policy alternative is pairwise compared to the other, in relation to each criterion, in order to assess the contribution of each policy alternative to each criterion. Priorities of the assessor for the alternatives are manually inserted into Expert Choice. Priorities are expressed in relative ratio scores. Subsequently, the software programme synthesizes the judgements automatically by aggregating 
the ratio scores for each criterion and the overall objective, in relation to each policy alternative. The logical consistency mechanism verifies the consistency in the assessor's judgements. Finally, the priority matrix is constructed, ranking the most plausible policy alternatives in relation to sustainability.

\section{Indicators for setting priorities}

In order to compare each policy alternative pairwise to the other, in relation to each assessment criterion, the assessor needs to know how each alternative complies with each criterion. Indicators can advice the policy-makers in which policy priority meet the correct criteria terms. This section ascribes indicators to the assessment criteria, which can support the assessor in comparing the five speed enforcement policy alternatives.

\subsection{Social criteria}

\subsubsection{Traffic safety}

A literature review shows that particular speed enforcement policy measures on freeways are more effective than others. Fixed speed cameras on motorways reduce $44,33 \%$ of all injury accidents, within a range of $500 \mathrm{~m}$ around the camera location [16]. ISA and section control are estimated to reduce all injury accidents with respectively $36 \%$ and $33 \%$ [17, 18]. Mobile speed enforcement measures with or without interception are less effective with reductions around 12 and $15 \%$ respectively [19]. A lexicographic model ranks the policy alternatives according their traffic safety effectiveness: manned speed surveillance with interception $<$ manned speed surveillance without interception $<$ unmanned speed cameras $<$ section control $<$ ISA.

\subsubsection{Traffic livability}

Traffic noise and toxin gas emissions are commonly used to gauge traffic livability. Traffic noise evokes redundant decibels. Toxin gas emissions, i.e., fine particles (PM10-PM2,5), ozone $\left(\mathrm{O}_{3}\right)$, nitrogen oxides $\left(\mathrm{NO}_{\mathrm{x}}\right)$, sulfur dioxide $\left(\mathrm{SO}_{2}\right)$, benzene $\left(\mathrm{C}_{6} \mathrm{H}_{6}\right)$ evoke bad air quality. Both emissions affect the human health. Vehicle speed [20] and driving practices [21] influence the emitted quantity of toxic gases and noise. Visible unmanned speed cameras induce, in contrary to invisible manned speed enforcement, mean speed harmonisations [22]. Harmonised speeds evoke less noise and toxin gas emissions from vehicles. If drivers are aware of the enforcement, speed is harmonised, causing less noise and gas emissions. Consequently, if visible speed enforcement covers more kilometres, speed is harmonised over a longer distance, reducing more emissions. According to these findings the different alternatives can be ranked lexicographically, inducing less noise and gas emissions: manned speed surveillance $<$ unmanned speed cameras $<$ section control $<$ ISA. 


\subsubsection{Attitudes}

Attitudes of drives towards policy strategies can be measured by questioning the drivers. A survey in the Netherlands about the perception of camera surveillance showed that all measures have a quite high acceptation rate. Mobile speed enforcement with interception is the least favourable enforcement measure $(58 \%)$. Section control (76\%), fixed speed cameras $(80 \%)$ and mobile speed control without interception (86\%) have a better acceptation rate [23]. The acceptance rate for ISA was found to be $69 \%$ [24]. The speed enforcement policy alternatives can be ranked according their social acceptability as follows: manned speed surveillance with interception $<$ ISA $<$ section control $<$ unmanned speed cameras $<$ manned speed surveillance without interception.

\subsection{Economic criteria}

\subsubsection{Traffic flow}

Speed enforcement measures intend to reduce the traffic speeds in order to augment the level of road safety, however this creates structural vehicle-loss hours for the road users who are driving slower than the speed they would drive without those measures. In this paper the traffic flow is measured by the speed reductions as a result of the measures. Positive effects such as the decrease of vehicle-loss hours as a result from the improved road safety level are not taken into account: manned speed surveillance $<$ unmanned speed cameras $<$ ISA $<$ section control.

\subsubsection{Implementation costs}

The implementation costs of the different alternatives are strongly related to the enforcement range. Therefore the implementation costs are expressed in Euros per kilometre enforced freeway. For Flanders with approximately 3700000 vehicles, an implementation cost $€ 440$ per vehicle [17] and around $1500 \mathrm{~km}$ highway the implementation cost is around $€ 1$ million per enforced kilometre. Section control implementation varies between $€ 150000$ and $€ 250000$ per enforced kilometre depending on the length of the section control. The investment cost of a fixed speed camera is around $€ 50000$, while a mobile speed camera is around $€ 70000$ to $€ 100000$. Hereby only a few meters are effectively enforced. The literature however assumes an effect (mobile and fixed speed cameras) within a range of at least $500 \mathrm{~m}$ around the camera location $[16,25]$. Considering the implementation costs, the policy alternatives can be ranked according their expenses: unmanned speed cameras $<$ manned speed surveillance without interception $<$ manned speed surveillance with interception $<$ section control $<$ ISA.

\subsubsection{Maintenance costs}

Maintenance costs include the calibration of the speed cameras, the cleaning and repairing of the camera housings and the back-office costs. Maintenance costs are calculated in the same way as the implementation costs, namely the cost per enforced kilometre. The maintenance costs for ISA are calculated based on [17], namely $£ 2.25$ million $+£ 1$ per vehicle. The Flemish government provided the 
maintenance costs of fixed, mobile speed cameras and section control. A lexicographic model ranks the speed enforcement policy alternatives according their expenses: ISA < unmanned speed cameras $<$ manned speed surveillance without interception $<$ section control $<$ manned speed surveillance with interception.

\subsection{Environmental criteria}

\subsubsection{Greenhouse gas emissions}

Greenhouse gas emissions strongly correlate with toxic gas emissions, induced by fuel combustion. Vehicle fuel combustion depends from vehicle speed [20] and the amount of accelerations and decelerations [21]. Unmanned speed cameras compel speed harmonisation effectively [22], evoking less fuel combustion and exhaust emissions. The more speed enforcement policy measures achieve speed harmonisation, the less exhaust gasses vehicles emit. These findings compose a lexicographic model for the greenhouse gas emission criteria: manned speed surveillance $<$ unmanned speed cameras $<$ section control $<$ ISA.

\subsubsection{Minimizing waste}

No studies have been found on recycling materials in relation to speed enforcement strategies on freeways. For this reason we consider the amount of primary products that are necessary to implement the different speed enforcement alternatives. ISA and section control imply the most primary products, because they cover longer distances. Unmanned fixed speed cameras necessitate the least primary products. These assumptions are lexicographically displayed: ISA $<$ section control $<$ manned speed surveillance with interception $<$ manned speed surveillance without interception $<$ unmanned speed cameras.

\section{Results of the multicriteria analysis}

Results of the multicriteria analysis are presented in four sensitivity performance figures. The way in which each speed enforcement policy alternative complies with each sustainability criteria, is pictured in a social, economic and environmental sensitivity performance figure. The overall sensitivity performance figure integrates the results of social, economic and environmental performance sensitivity, ranking the policy alternatives according their sustainability.

\subsection{Social performance}

ISA and section control are ranked as the most plausible social alternatives, based on the selected assessment criteria. Traffic safety and traffic livability effects of ISA and section control are high, while attitudes of drives towards the implementation are less positive, compared to the other policy alternatives. 


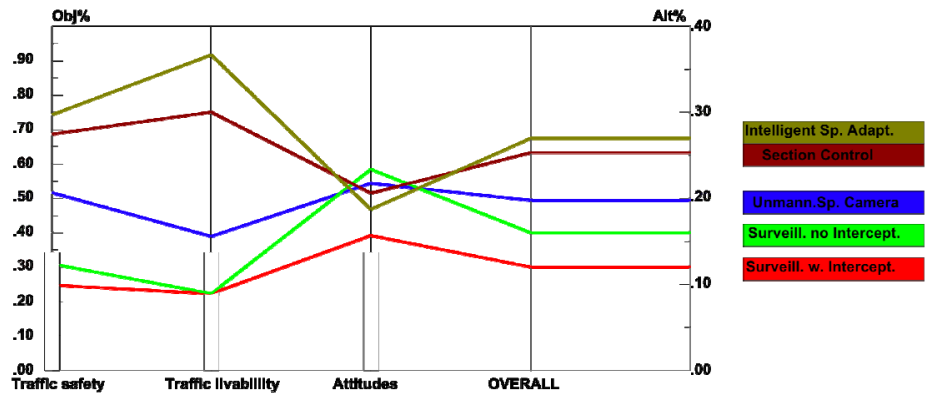

Figure 1: Performance sensitivity for the overall social criterion, per sub criterion. Source: own set up in Expert Choice.

The horizontal axes in the figures display the selected sub criteria. Each policy alternative is presented at the right side of the figure in five different colours. Vertical axes in the middle of the figure express the outcome of each alternative per criteria. The left axis designates the weights of the outcomes in relation to the objective. The right axis represents the scores of the outcomes in relation to the other alternatives. The vertical overall axis aggregates the outcomes of the sub criteria.

\subsection{Economic performance}

ISA and section control are economically the most plausible alternatives. Implementation costs are considered positive, since they enforce speed on longer sections of the highway.
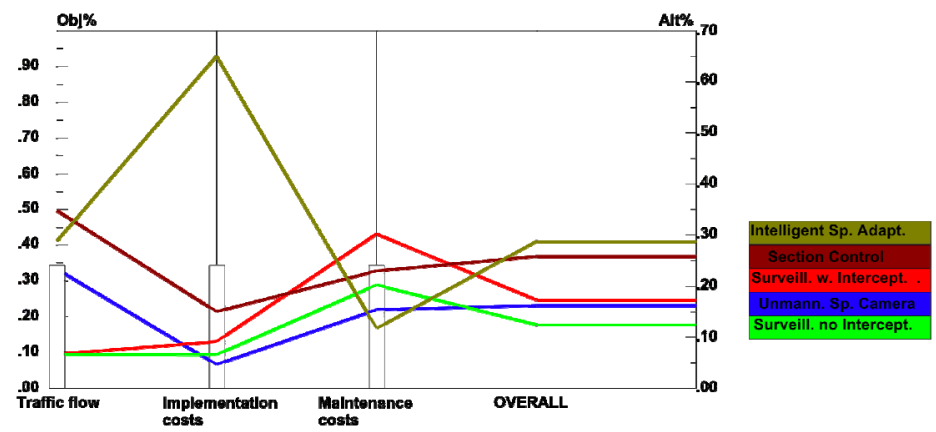

Figure 2: $\quad$ Performance sensitivity for the overall economic criterion, per sub criterion. Source: own set up in Expert Choice. 


\subsection{Environmental performance}

Unmanned speed cameras and ISA are environmentally the most credible alternatives. Unmanned speed cameras imply the least production materials. ISA and section control induce less $\mathrm{CO}_{2}$ emissions related to the other alternatives.

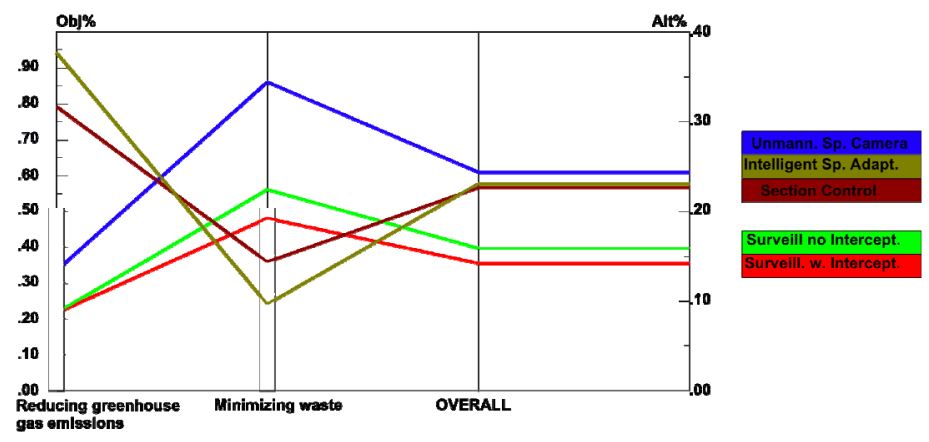

Figure 3: Performance sensitivity for the overall ecologic criterion, per sub criterion. Source: own set up in Expert Choice.

\subsection{Overall performance}

ISA and section control are ranked as the most sustainable policy alternatives, based on the selected sustainability criteria. Manned surveillance is disclosed as the least sustainable policy alternative.
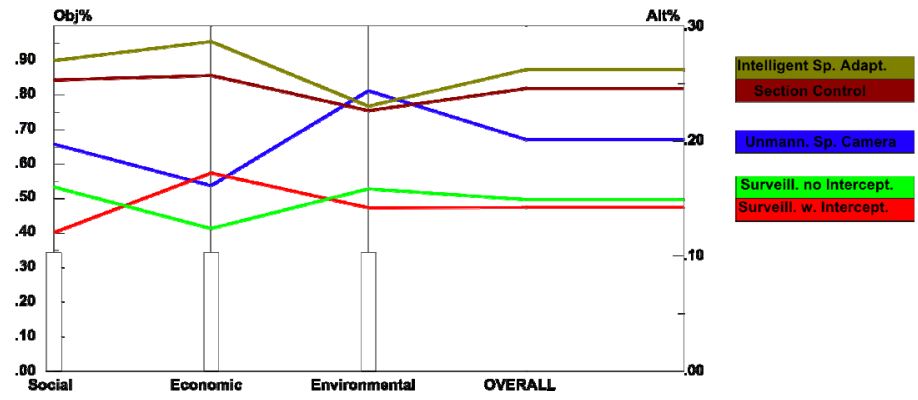

Figure 4: Performance sensitivity for the overall objective, per criterion. Source: own set up in Expert Choice.

\section{Conclusion}

Implementation of speed enforcement policy strategies on highways is effective in counteracting excessive speed and traffic accidents. Any speed enforcing strategy improves business as usual, where inappropriate speed behaviour is not compelled. However, when policy makers consider the implementation of 
additional and/or new speed enforcement strategies, the identification of unexpected social, economic and ecological effects can be meaningful in transitions towards sustainable societies. Conflicting social, economic and environmental objectives however impede the decision process. This study demonstrates that the multicriteria analysis can be very efficient in analyzing conflicting sustainability objectives. Compromise policy alternatives are suggested, whose contribution to each qualitative and quantitative sustainability criterion is determined.

The case of the speed enforcement policy strategies on highways clearly illustrates that particular policy measures are more preferable, in relation to sustainability, then others. Prospective speed enforcement strategies like ISA and section control are considered to be more sustainable than conventional enforcement strategies, based on the selected assessment criteria.

\section{References}

[1] Santos, G., Behrendt, H., Maconi, L., Shirvani, T. \& Teytelboym, A., Part I: Externalities and economic policies in road transport. Research in Transportation Economics, 28(1), pp. 2-45. 2010.

[2] Mihic, S., Golusin, M. \& Mihajlovic, M., Policy and promotion of sustainable inland waterway transport in Europe - Danube River. Renewable and sustainable Energy Reviews, 15(4), pp. 1801-1809, 2011.

[3] Wegman, F.C.M., Aarts, L \& Bax, C., Advancing sustainable safety: National road safety outlook for the Netherlands for 2005-2020. Safety Science 46(2), 323-343, 2008.

[4] Peden, M., Scurfield, R., Sleet, D., Mohan, D., Hyder, A.A., Jarawan, E. \& Mathers, C. World report on road traffic safety prevention. Geneva: World Health Organisation, 2004.

[5] Chen, G., Wilson, J., Meckle, W. \& Cooper, P., Evaluation of photo radar program in British Columbia. Accident Analysis and Prevention 32(4): $517-$ 526, 2000.

[6] Aerts, L., \& van Schagen, I.N.L.G., Driving speed and the risk of road crashes: a review. Accident Analysis and Prevention 38(2), pp. 215-224, 2006.

[7] Elvik, R. \& Vaa, T., Handbook of road safety measures. Amsterdam, Elsevier, 2004.

[8] Macharis, C., Springael, J., De Brucker, K. \& Verbeke, A., PROMETHEE and AHP: The design of operational synergies in multicriteria analysis. Strengthening PROMETHEE with ideas of AHP. European Journal of Operational Research 153(2), pp. 307-317, 2004.

[9] Damart, S. \& Roy, B., The use of cost-benefit analysis in public transportation decision-making in France. Transport Policy, 16(4) pp. 200212, 2009.

[10] Munda, G., Social multi-criteria evaluation for a sustainable economy. Springer-Verlag: Berlin, 2008. 
[11] Saaty, T.L., Decision making for leaders. Lifetime learning publications. Wadsworth: Belmont, 1982.

[12] Wegman, F.C.M. \& Goldenbeld, C., Speed management: enforcement and new Technologies. SWOV-rapport R-2006-05, 2006.

[13] Flemish Department MOW, Verkeersveiligheidplan Vlaanderen. Brussels, Ministry of the Flemish Community, 2008.

[14] EC, Annexes to impact assessment guidelines. SEC, 2009.

[15] Hess, S., Analysis of the Effects of Speed Limit Enforcement Cameras. Differentiation by Road Type and Catchment Area. TRB: Journal of the Transportation Research Board. 1865, pp.28-34, 2004.

[16] Carsten, O.M.J. \& Tate. F.N., Intelligent speed adaption: accident savings and cost-benefit analysis. Accident analysis \& Prevention. 37(3), pp. 407416, 2005.

[17] Stefan, C., Section Control - Automated speed enforcement in the Kaisermühlen tunnel. Austrian Road Safety Board, 2006.

[18] Keall, M.D., Povey, L.J., \& Frith, W.J., The relative effectiveness of a hidden versus a visible speed camera programme. Accident analysis and prevention, 33(2), pp. 277-284, 2001.

[19] Shawarby, I., Ahn, K. \& Rakha, H., Comparative field evaluation of vehicle cruise speed and acceleration level impacts on hot stabilized emissions. Transportation Research Part D, 10(1), pp. 13-30, 2005.

[20] Jayaratne, E.E., Wang, L., Heuff, D., Morawska, L., Ferreira, L., Increase in particle number emissions from motor vehicles due to interruption of steady traffic flow. Transportation Research Part D, 14(7), pp. 521- 526, 2009.

[21] Shin, K., Washington S.P. \& van Schalkwyk, I., Evaluations of the Scottsdale Loop 101 automates speed enforcement demonstration programme. Accident Analysis and Prevention, 42(2), pp. 393-403, 2009.

[22] Poppeliers, R., Scheltes, W. \& in 't Veld, N., Effectmeting regioplannen. Landelijke rapportage 2008. Onderzoek BVOM. Rijswijk, Nederland., 2009.

[23] De Mol, J. \& Vlassenroot, S., ISA-project Gent: Grote aanvaardbaarheid bij de bestuurders van intelligente snelheidsaanpassing. Bijdrage aan Colloquium Vervoersplanologisch Speurwerk, Zeist., 2004.

[24] Christy, S.M., Lyons, R.A., Dunstan, F.D. \& Jones, S.J., Are mobile speed cameras effective? A controlled before and after study. Injury Prevention, 9, pp. 302-306, 2003. 